\title{
Assessment of Inhalation Risk to Children's Health Under the Exposure of Chemicals Migrating From Furniture Products
}

\author{
May I.V.* Nikiforova N.V. \\ Federal Scientific Research Center for Medical and Preventive Health Risk Management Technologies, Perm, Russia \\ *Corresponding author. Email: may@fcrisk.ru
}

\begin{abstract}
A research of the furnishing level of preschool establishments has been conducted, the air quality of the premises has been assessed for the presence of chemical impurities (formaldehyde, phenol, benzene, styrene, ethylbenzene) migrating from furniture products and forming the chronic risks to children's health, attending pre-school organizations. It has been established that the furnishing level of the premises of preschool educational institutions varies from 0.35 to $1.15 \mathrm{~m}^{2} / \mathrm{m}^{3}$. The dependence between the formaldehyde content in the indoor air and the furnishing level of these premises $\left(y=0.0128 x+0.0035, R^{2}=0.23\right)$ was obtained. The maximum permissible average daily concentrations of formaldehyde $(25 \%$ of values exceed the hygienic standard of $\mathrm{MPC}_{\mathrm{ad}}$ from 2 to 9 times) and phenol (25\% of values exceed the hygienic standard of $\mathrm{MPC}_{\mathrm{ad}}$ from 1.7 to 5 times) were established. Unacceptable risk levels of development of non-carcinogenic effects on the children's health are forecasted in relation to respiratory system 3,0-7,5 HI $(69,7-100 \%$ of the contribution to risk formation is made by formaldehyde), to immune system - 3,9 HI of $8.8(61,0-84.4 \%$ of the contribution is made by formaldehyde). For cardiovascular and central nervous systems risks are forecasted at the level of $0,9-3,8 \mathrm{HI}(40,4-100 \%$ of the contribution is made by benzene). The median of total carcinogenic risk (TCR) averaged $9.8 \times 10^{-5}$. This level of risk corresponds to the upper limit of the acceptable level of risk.
\end{abstract}

Keywords: indoor air, inhalation risk, children's health, preschool educational institutions, formaldehyde

\section{INTRODUCTION}

The preservation of children's health and development of their abilities is included in the strategic interests of the state. The priority of children's health protection is stipulated in the Federal law «On the protection of citizens' health». There are more than 113,000 preschool and secondary educational institutions in the Russian Federation, attended by about 19 million children. According to some researchers, the contribution of the conditions of children education and upbringing to the formation of the younger generation health is about 28-35\% [1]. A number of studies have established a significant role of indoor air quality, including in educational institutions, in the occurrence of diseases in children and adolescents [2, 3]. In the premises, potential sources of air pollution can be polymer and polymer-containing materials, toys, human activities, atmospheric air, coming from the ventilation of premises and so on. [4]. Building and finishing materials and furniture products are significant sources of indoor air pollution. This type of product may contain polymers that are added to improve its properties. For example, one of the most popular polymers in the production of building and finishing materials and furniture products are formaldehyde-containing resins. They are used as binding components of various fillers, such as shavings, sawdust and so on. High reactivity, stability and the presence of disinfectant, bactericidal and preservative properties of formaldehyde resin allow it to be used in the production of compounds that give materials hardness, rigidity and resistance to biological hazard factors [5].

In addition to the positive properties of composite materials, there are also some disadvantages of them - the migration of chemicals that are not safe for human health from the surface of materials to the air [6]. Potential indoor pollutants include formaldehyde, toluene, ethylbenzene, styrene, phenol, phthalates and so on. [7-12].

Migration of these substances from the surface of the material can be caused by various reasons, such as gradual aging, destruction of the polymer, chemical interaction with moisture and so on.

At the same time, a number of researchers have found that migration of chemical impurities from the surface of the material to the environment can be significant [13]. As a result, chemicals, containing in indoor air, can have an adverse effect on the health and well-being of a person, especially a child $[2,3]$.

All these facts actualize the problem of studying the influence of indoor air quality on the children's health. 


\section{METHODS AND MATERIALS}

The aim of the research was to assess the chronic carcinogenic and non-carcinogenic inhalation risk to children's health, formed by the presence of chemical impurities in the air of preschool institutions.

The research was conducted in 19 typical preschool organizations.

Within the research, we calculated the furnishing level of premises of preschool organizations. We performed a direct measurement of the total area of furniture products and correlated the resulting value with the value of the room volume in accordance with MU 2.1.2.1829-04 of 06.01.2004 «Sanitary and hygienic assessment of polymer and polymer-containing building materials and structures intended for use in the construction of residential, public and industrial buildings». The parameters for the volume of premises are taken from the documentation for buildings of preschool organizations.

The building and finishing materials and furniture used in the premises were evaluated visually. The period of furniture maintenance was established based on the results of surveys of institution employees.

Within the research, instrumental studies were performed on the content of formaldehyde, phenol, ethylbenzene, benzene, styrene in the air of premises and in the atmospheric air of the territories of preschool institutions. Air quality was studied for the content of chemicals in 56 game rooms (from 1005 to 1011 samples for individual impurities). The research of air samples was carried out in accordance with the approved methods of GOST 17.2.3.01-86 «Nature protection. Atmosphere. Rules for air quality control of localities», GOST R ISO 16000-1-2007 «Air of closed premises. Part 1. Sampling. Generalities». Sampling was performed by active sampling in different seasons of the year - in cold (heating) and warm (non-heating) periods. On the territory of preschool institutions, as well as in the game rooms, 3 samples a day were taken for 3 days in each institution. For the subsequent assessment of exposure to chemicals, the arithmetic mean of single concentrations selected during one day was calculated. Determination of the studied chemical impurities in air samples was carried out according to standardized methods - MUK 4.1.1045-01, MUK 4.1.662-97, RD 52.04.186-89 p.5.3.5.1, RD 52.04.186-89 p. 5.3.3.5. The methods were gas and highperformance liquid chromatography. The quality of air in premises and atmospheric air in the institution territories according to the content of the studied chemical components was evaluated for compliance with hygiene standards-GN 2.1.6.1338-03 "Maximum permissible concentrations (MPC) of pollutants in the atmospheric air of urban and rural settlements".

Linear regression analysis was used to assess whether the chemical content in the indoor air depends on the furnishing level of the premises. The reliability of the obtained model was evaluated using the Styudent's criterion. The dependence was considered reliable at $\mathrm{p}<0.05$.
The assessment of the inhalation risk to the children's health attending preschool institutions from exposure to the studied chemicals was carried out in accordance with $\mathrm{R}$ 2.1.10.1920-04 "Guidelines for assessing the risk to public health from exposure to chemicals that pollute the environment". The script of the exposition was formed taking into account the presence of children during the day in different conditions: air in preschool institutions, atmospheric air, and air in residential apartments. To assess the non-carcinogenic and carcinogenic inhalation risk, the values of the average concentrations of chemical impurities in the air of educational institution premises and the atmospheric air of the territories, where institutions are located (outdoor games), were used for the selection period. To characterize the content of the studied substances in the air of residential premises, data from scientific literature were used [4]. To assess the time spent by children in different air environments, the daily routine of preschool organizations was analyzed. Exposure was assessed using standard exposure factors. To assess noncarcinogenic risk, hazard coefficients and indices (HQ, HI) were calculated. HQ and HI values equal to or less than 1.0 were considered acceptable. To characterize the carcinogenic risk, individual risk indicators were calculated and evaluated in accordance with $R$ 2.1.10.1920-04 "Guidelines for assessing public health risk from exposure to chemicals that pollute the environment". A risk level of less than $1 \times 10^{-4}$ was considered acceptable.

\section{RESULTS}

The results of inspection of the premises and the survey of preschool employees showed that the decoration of the premises was presented by - walls - water-based paint, floor - linoleum, ceiling - whitewash. On average, the repair of premises was completed 1-3 years before the research. The age of furniture at the time of the research was on average 5-6 years. The premises volume of play preschool institutions varied in the range of $123.3-176.4 \mathrm{~m}^{3}$ $\left(50 \%\right.$ - percentile $\left.-150.53 \mathrm{~m}^{3}\right)$. The furnishing index in gaming rooms was in the range of $0.35-1.15 \mathrm{~m}^{2} / \mathrm{m}^{3}, 50 \%-$ percentile $-0.63 \mathrm{~m}^{2} / \mathrm{m}^{3}$ ) (Figure 1).

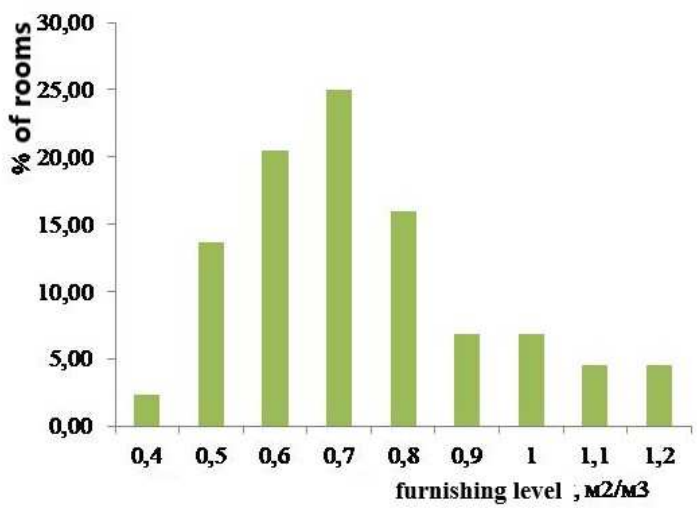

Figure 1 The furnishing level in preschool play organizations, $\mathrm{m}^{2} / \mathrm{m}^{3}$ 
The results of the air quality assessment of preschool institution premises and the territory of preschool educational institutions on the content of the studied substances indicated that formaldehyde and benzene were most often quantified in the air of premises (the percentage of samples with a value above the determination threshold was 98.8 and $99.1 \%$, respectively). While only 1.6-29.0\% of air samples for the content of phenol, styrene, and ethylbenzene were in the values above the threshold for determining the chemical-analytical method of research. With regard to atmospheric air, the situation is similar. As a result, styrene and ethylbenzene were subsequently excluded from the analysis.

To assess chronic exposure, the arithmetic mean of single concentrations selected during one day was compared with the MPC adfor the analyzed substances. The distribution results of pollutant concentrations and their ratio to the MPS ad are presented in table 1.

Table 1 Hygienic assessment of the content of formaldehyde, benzene, phenol in the air of preschool institutions (concentrations averaged over the selection period, $\mathrm{mg} / \mathrm{m}^{3}$ )*

\begin{tabular}{|c|c|c|c|c|c|c|}
\hline \multirow{2}{*}{ Indicator } & \multicolumn{2}{|c|}{ Formaldehyde } & \multicolumn{2}{|r|}{ Benzene } & \multicolumn{2}{|r|}{ Phenol } \\
\hline & $\begin{array}{c}\text { The } \\
\text { value }\end{array}$ & $\begin{array}{c}\text { The multiplicity } \\
\text { of excess } \mathrm{MPC}_{\mathrm{ad}} \\
0.01 \mathrm{mg} / \mathrm{m}^{3}\end{array}$ & $\begin{array}{c}\text { The } \\
\text { value }\end{array}$ & $\begin{array}{c}\text { The multiplicity of } \\
\text { excess } \mathrm{MPC}_{\mathrm{ad}} \\
0.1 \mathrm{mg} / \mathrm{m}^{3}\end{array}$ & $\begin{array}{c}\text { The } \\
\text { value }\end{array}$ & $\begin{array}{c}\text { The multiplicity of } \\
\text { excess MPC } \\
0.006 \mathrm{mg} / \mathrm{m3}\end{array}$ \\
\hline Median & 0.01 & 1 & 0.02 & 0.2 & 0.007 & 1.2 \\
\hline the 25 -th persentile & 0.006 & 0.6 & 0.01 & 0.1 & 0.006 & 1.0 \\
\hline the 75-th persentile & 0.02 & 2 & 0.04 & 0.4 & 0.01 & 1.7 \\
\hline the 95-th persentile & 0.04 & 4 & 0.07 & 0.7 & 0.019 & 3.2 \\
\hline Maximum & 0.09 & 9 & 0.2 & 2 & 0.03 & 5.0 \\
\hline
\end{tabular}

* For ethylbenzene and styrene, the hygienic assessment was not carried out due to the large number of concentration values below the threshold for determining the chemical-analytical method of research.

As a result of hygienic evaluation of containing of formaldehyde, benzene, phenol in indoor air of preschool institutions was established that the excess of maximum permissible average daily concentrations recorded by such substances as formaldehyde ( $25 \%$ of the values exceed the $\mathrm{MPC}_{\mathrm{ad}}$ standard from 2 to 9 times), phenol (25\% of the values exceed the $\mathrm{MPC}_{\mathrm{ad}}$ standard from 1.7 to 5 times).
Analysis of the air quality of preschool territories showed that the content of the studied chemicals in the air corresponded to the hygienic standards ( $\mathrm{MPC}_{\mathrm{ad}}$ ) (table 2), with the exception of phenol. Phenol was quantified in $30.7 \%$ of atmospheric air samples, and $45.7 \%$ of them did not correspond the hygienic requirements for the phenol content in the air.

Table 2 The content levels of chemical impurities in the atmospheric air in the territories of preschool organizations (concentrations averaged over the selection period), $\mathrm{mg} / \mathrm{m}^{3}$

\begin{tabular}{|c|c|c|c|}
\hline \multirow{2}{*}{ Indicator } & Formaldehyde & Benzene & Phenol \\
\hline & $\mathrm{MPC}_{\mathrm{ad}}=0,01 \mathrm{M \Gamma} / \mathrm{M}^{3}$ & $\mathrm{MPC}_{\mathrm{ad}}=0,100 \mathrm{M \Gamma} / \mathrm{M}^{3}$ & $\mathrm{MPC}_{\mathrm{ad}}=0,006 \mathrm{Mr} / \mathrm{M}^{3}$ \\
\hline Median & 0.0012 & 0.0088 & 0.006 \\
\hline the 25 th percentile & 0.0004 & 0.0063 & 0.004 \\
\hline the 75 th percentile & 0.0021 & 0.0150 & 0.009 \\
\hline the 95th percentile & 0.0051 & 0.0393 & 0.012 \\
\hline Maximum & 0.01 & 0.0757 & 0.014 \\
\hline
\end{tabular}

The concentrations of formaldehyde in the air of the premises in pre-school organizations accurately exceeded the corresponding levels of impurity in the ambient air up to $125-150$ times $(\mathrm{p}<0.05)$. Thus, it was concluded that the elevated formaldehyde levels inside the premises were the result of the availability of indoor sources, including furniture. According to the results of the research, the change in the concentration of formaldehyde in the air of play rooms in pre-school institutions was determined by the fact that the premises were saturated with furniture 
products. The type of dependence was represented by equation $\quad \mathrm{y}=0.0128 \mathrm{x}+0.0035 \quad\left(\mathrm{R}^{2}=0.23\right)$. Reliable dependencies were not found for other chemical impurities. The obtained dependence can be used in planning the filling of play rooms in pre-school educational institutions with furniture in order to establish the expected concentrations of formaldehyde in the air of the premises.

Table 3 Hazard coefficients $\left(\mathrm{HQ}_{\mathrm{cr}}\right)$ for chronic exposure to formaldehyde, benzene present in the air of preschool educational organizations
The assessment of chronic inhalation risk to children's health, under formaldehyde exposure, expressed by hazard coefficients $\left(\mathrm{HQ}_{\mathrm{cr}}\right)$, showed that the median $\mathrm{HQ}_{\mathrm{cr}}$ was 4.02 (the 95th percentile $\mathrm{HQ}_{\mathrm{cr}}-5.64$ ), under benzene exposure the median $\mathrm{HQ}_{\mathrm{cr}}$ was 1,2 (the 95th percentile $\mathrm{HQ}_{\mathrm{cr}}-1.85$ ), under phenol exposure the median $\mathrm{HQ}_{\mathrm{cr}}$ was 0.12 (the 95th percentile $\mathrm{HQ}_{\mathrm{cr}}-1.85$ ) (table 3).

\begin{tabular}{|c|c|c|c|c|c|c|}
\hline \multirow[b]{2}{*}{ Indicator, $\mathrm{mg} / \mathrm{m}^{3}$} & \multicolumn{2}{|l|}{ Formaldehyde } & \multicolumn{2}{|l|}{ Benzene } & \multicolumn{2}{|l|}{ Phenol } \\
\hline & $\begin{array}{l}\text { Effective } \\
\text { concentration, } \\
\mathrm{mg} / \mathrm{m}^{3}\end{array}$ & $\mathrm{HQ}_{\mathrm{cr} *}$ & $\begin{array}{l}\text { Effective } \\
\text { concentration, } \\
\mathrm{mg} / \mathrm{m}^{3}\end{array}$ & $\mathrm{HQ}_{\mathrm{cr} *}$ & $\begin{array}{l}\text { Effective } \\
\text { concentration, } \\
\mathrm{mg} / \mathrm{m}^{3}\end{array}$ & $\mathrm{HQ}_{\mathrm{cr}}$ \\
\hline Median & 0.012 & 4.02 & 0.036 & 1.20 & 0.0035 & 0.58 \\
\hline the 25 th percentile & 0.010 & 3.46 & 0.030 & 1.01 & 0.000 & 0 \\
\hline the 95th percentile & 0.014 & 4.78 & 0.043 & 1.45 & 0.0062 & 1.0 \\
\hline the 95th percentile & 0.017 & 5.64 & 0.056 & 1.85 & 0.0086 & 1.4 \\
\hline Maximum & 0.021 & 7.01 & 0.098 & 3.28 & 0.0093 & 1.5 \\
\hline
\end{tabular}

* calculated for the values of average annual concentrations at the level of maximum daily average values

Assessment of the chronic inhalation risk of children's health, under formaldehyde, benzene, phenol exposure, expressed by the hazard indices, showed that hazard index for respiratory organs is predicted at level of 3.0-7.5 HI (69.7-100\% of the contribution to the formation of risk is made by formaldehyde), for the immune system $-3.9 \mathrm{HI}$ of $8.8,(61.0-84.4 \%$ of the contribution is made by formaldehyde), for cardiovascular and central nervous systems $-0.9-3.8 \mathrm{HI}(40.4-100 \%$ of the contribution is made by benzene)(table 4 ).

Table 4 Hazard indices $\left(\mathrm{HI}_{\mathrm{cr}}\right)$ of the development of non-carcinogenic health effects in chronic exposure to formaldehyde, benzene, phenol present in the air of pre-school educational organizations

\begin{tabular}{|l|c|c|c|}
\hline Indicator & $\begin{array}{l}\text { HI respiratory } \\
\text { organs }\end{array}$ & HI the immune system & $\begin{array}{l}\text { HI cardiovascular system, } \\
\text { central nervous system }\end{array}$ \\
\hline Minimum & 3.0 & 3.9 & 0.9 \\
\hline the 25th percentile & 4.0 & 4.6 & 1.4 \\
\hline Median & 4.7 & 6.3 & 2.3 \\
\hline the 75th percentile & 5.5 & 7.6 & 3.0 \\
\hline the 95th percentile & 6.6 & 8.8 & 3.8 \\
\hline Maximum & 7.5 & & \\
\hline
\end{tabular}

Thus, the calculated hazard indices for the respiratory, immune, central nervous and cardiovascular systems allow us to assess the risk as unacceptable for children's health (HI>1).

The assessment of the carcinogenic risk for children attending pre-school institutions showed that the median of individual carcinogenic risk (CR) from inhalation of formaldehyde averaged $3.3 \times 10^{-5}$ for pre-school institutions, of benzene $-6.5 \times 10^{-5}$, and was evaluated as acceptable (table 5). 
Table 5 Indicators of individual and general carcinogenic risk to the health of children with chronic exposure to formaldehyde, benzene present in the air of pre-school educational organizations

\begin{tabular}{|c|c|c|c|}
\hline Indicator & CR formaldehyde & CR benzene & TCR \\
\hline Minimum & $2.2 \times 10^{-5}$ & $4.5 \times 10^{-5}$ & $8.1 \times 10^{-5}$ \\
\hline the 25th percentile & $2.8 \times 10^{-5}$ & $5.6 \times 10^{-5}$ & $9.8 \times 10^{-5}$ \\
\hline Median & $3.3 \times 10^{-5}$ & $7.9 \times 10^{-5}$ & $1.2 \times 10^{-4}$ \\
\hline the 75th percentile & $3.9 \times 10^{-5}$ & $1.1 \times 10^{-4}$ & $1.5 \times 10^{-4}$ \\
\hline the 95th percentile & $5.63 \times 10^{-5}$ & $1.8 \times 10^{-4}$ & $2.2 \times 10^{-4}$ \\
\hline
\end{tabular}

The median of total carcinogenic risk (TCR) averaged $9.8 \times 10^{-5}$. This level of risk corresponds to the upper limit of the acceptable level of risk.

\section{CONCLUSION}

Furniture and finishing materials, due to the features of modern production and widespread use of polymeric components, are one of the sources of indoor air pollution with chemicals, which in turn affect human health.

The results of studying the furnishing of premises in pre-school educational institutions showed that the furnishing index varies in the range from $0.35-1.15 \mathrm{~m}^{2} / \mathrm{m}^{3}$, $50 \%$ - percentile $-0,63 \mathrm{~m}^{2} / \mathrm{m}^{3}$ ).

The dependence between the formaldehyde content in the air and the furnishing of premises is established, which can be described by the following equation $\mathrm{y}=0.0128 \mathrm{x}+0.0035\left(\mathrm{R}^{2}=0,23\right)$.

Formaldehyde and benzene were found everywhere in significant concentrations in the indoor air and in the atmospheric air of the territories in pre-school institutions. The concentrations of pollutants in the indoor air significantly exceeded the corresponding values of atmospheric air, for formaldehyde up to 150 times $(p<0.05)$. Thus, elevated formaldehyde levels inside the premises were attributed to internal sources of pollution, including furniture.

In the air of the premises in pre-school organizations, the exceedance of the maximum permissible average daily concentrations for substances such as formaldehyde $(25 \%$ of the values above MPC ad from 2 to 9 times) and phenol ( $25 \%$ of the values above MPC ${ }_{\text {ad With a multiplicity from }}$ 1.7 to 5 times) was registered.

Unacceptable levels of risk for the development of non-carcinogenic effects on children's health were established. For respiratory organs the hazard index is predicted at level of 3.0-7.5 HI (69.7-100\% of the risk was contributed by formaldehyde), for the immune system - 3.9-8.8 HI (61.0-84.4\% of the contribution was made by formaldehyde) and for cardiovascular and central nervous systems the level is predicted to be $0.9-3.8 \mathrm{HI}$ (40.4-100\% of the contribution was made by benzene).

The median total carcinogenic risk (TCR) averaged $9.8 \times 10^{-5}$, this level of risk corresponds to the upper limit of the acceptable risk level.

On the basis of the obtained results, recommendations were formulated to minimize the risk to children's health:

- preliminary assessment of the furnishing of premises in order to predict the concentration of chemicals originating from furniture;

- $\quad$ gradual transition to using furniture with minimal levels of chemical emissions into the environment;

- $\quad$ strict compliance with the ventilation regime of premises in any season of the year;

- $\quad$ organization and implementation of prevention programs aimed at early detection of deviations in the health of children due to exposure to substances present in the indoor air.

\section{REFERENCES}

[1] V.M. Kuchma, Hygiene of children and adolescents, GEOTAR-Media, Moscow, 2008, 480 p.

[2] O.Iu. Ustinova, S.L. Valina, O.A. Kobiakova et al., Justification of optimum filling of groups of preschool educational organizations with general development orientation, Hygiene and sanitat., 95(1) (2016) 57-63.

[3] N.V. Nikiforova, I.V. Mai, V.S. Evdoshenko et al., Living conditions and health status of the residents of prefabricated timber frame houses of subdistrict Usolskii-2 (Berezniki, Perm territory), Hygiene and sanitat. 96(1) (2017) 40-44.

[4] Iu.D. Gubernskii, Public health risk assessment of chemicals that pollute residential air, Hygiene and sanitat. 6 (2006) 27-30. 
[5] J.F. Walker, Formaldehyde Second edition, American Chemical Sosiety Monograph Series, New York, 1953, 608 p.

[6] Iu.D. Gubernskii, N.V. Kalinina, For building materials to be safe, Sanitary control 6 (2012).

[7] A.A. Gladkovskaia, Hygiene, Novosibirsk, 1968, pp. $98-104$.

[8] M.J. Mendell, Indoor residential chemical emission as risk factors for respiratory and allergic effects in children, Indoor air 17(4) (2007) 259-277.

[9] Iu.S. Drugov, L.A. Konopelko, O.G. Popov, Air control of residential premises, offices, administrative and public buildings, Science, St. Petersburg, 2013, 302 p.
[10] V.B. Khabarov, Health and chemical characteristics of composite wood materials and synthetic resins according to gas chromatography, Sorption and chromatographic processes 15(2) (2015) 196-215.

[11] T. Salthammer, S. Mentese, R. Marutzky, Formaldehyde in the Indoor Environment, Chem. Rev. 110(4) (2010) 2536-2572.

[12] S. Kim, Control of formaldehyde and TVOC emission from wood-based flooring composites at various manufacturing processes by surface finishing, J. of Hazardous Mater. 176 (2010) 14-19.

[13] E.M. Razinkov, Formaldehyde migration from wood chips, The forestry techn. J. 4(12) (2013) 117-125. 